\title{
ESTÁGIO SUPERVISIONADO EM LÍNGUA ITALIANA III - TUTORIA ON LINE
}

RIO DE JANEIRO/RJ MAIO/2018

\author{
Carmem Lucia Pereira Praxedes - UERJ - clppraxedes@gmail.com \\ Alcebiades Martins Arêas - UERJ - bideareas@gmail.com \\ Veridiana Skocic - UERJ - veridianaskocic@gmail.com
}

Tipo: Relato de Experiência Inovadora (EI)
Categoria: Conteúdos e Habilidades
Setor Educacional: EDUCAÇÃO SUPERIOR

RESUMO

A disciplina Estágio Supervisonado em Língua Italiana III - Tutoria on line foi proposta pela primeira vez no currículo de 2006, em ocasião da reforma das licenciaturas determinada pelo Governo Federal. Mas, somente em 2009/2, ela foi efetivamente oferecida aos estudantes, devido ao seu meio de realização ser diferenciado, i. é; o ambiente virtual - ava. Desde então, a referida disciplina foi refeita a partir da discussão dos docentes, estagiários e estudantes nela envolvidos conjuntamente ao pessoal técnico do Laboratório de Tecnologias da Informação e Comunicação - Latic/UERJ, contando com o financiamento da CAPES/UAB em 2012. Atualmente, ela necessita ser reorganizada, seguindo a dinâmica da constante revisão de saberes e estratégias. A sua proposição, organização e realização seguiu os pressupostos do projeto Implementação da Licenciatura em Letras - Habilitação PortuguêsItaliano e respectivas Literaturas, de nossa autoria e coordenação. Tínhamos o entendimento de que $o$ estágio supervisionado fosse visto como momento concretizador da formação do licenciando, espaço de aplicação das teorias de ensino-aprendizagem de línguas estrangeiras, bem como de integração com as novas tecnologias da comunicação e informação. A linguagem, a motivação, o perfil desejável do aluno-on-line. Entre os objetivos da disciplina destacam-se: Proporcionar ao aluno vivências da prática docente de língua estrangeira on-line, supervisionado por docente UERJ. Articular as teorias sobre o ensino de LE à prática docente. Propor, aplicar e corrigir exercícios on-line, interagindo com estudantes que façam uso desta modalidade de ensino.

Palavras-chave: EAD UERJ, Italiano UERJ, Educação a Distância, Tutoria on line

\section{AGRADECIMENTOS}

\section{CAPES UAB}

UERJ 


\section{Introdução}

A disciplina Estágio Supervisionado em Língua Italiana III - Tutoria on-line foi proposta pela primeira vez no currículo de 2006, em ocasião da reforma das licenciaturas determinada pelo Governo Federal. Mas, somente em 2009/2, ela foi efetivamente oferecida aos estudantes, devido ao seu meio de realização ser diferenciado, i. é; o ambiente virtual - ava. Desde então, a referida disciplina foi refeita a partir da discussão dos docentes, estagiários e estudantes nela envolvidos conjuntamente ao pessoal técnico do Laboratório de Tecnologias da Informação e Comunicação - Latic/UERJ, tendo contado, inclusive, com o financiamento da CAPES/UAB em 2012. Atualmente, ela necessita ser atualizada, seguindo a dinâmica da constante revisão de saberes e estratégias. Inicialmente, a proposição, organização e realização da disciplina seguiu os pressupostos do projeto Implementação da Licenciatura em Letras - Habilitação Português-Italiano e respectivas Literaturas, de nossa autoria e coordenação. Tínhamos o entendimento de que o estágio supervisionado fosse visto como momento concretizador da formação do licenciando, espaço de aplicação das teorias de ensinoaprendizagem de línguas estrangeiras, bem como de integração com as novas tecnologias da comunicação e informação. A linguagem, a motivação, o perfil desejável do aluno on-line. Entre os objetivos da disciplina destacam-se: Proporcionar ao aluno vivências da prática docente de língua estrangeira on-line, supervisionado por docente UERJ; articular as teorias sobre o ensino de LE à prática docente; propor, aplicar e corrigir exercícios on-line, interagindo com estudantes que façam uso desta modalidade de ensino.

\section{A ESLIII}

A disciplina Estágio Supervisionado em Língua Italiana III, Tutoria on-line - ESLIII foi proposta pela primeira vez no currículo de 2006, em ocasião da reforma das licenciaturas determinada pelo Governo Federal. Mas, somente em 2009/2, ela foi efetivamente oferecida aos estudantes, devido ao seu meio de realização ser diferenciado, i. é; o ambiente virtual - ava, a disponibilidade dos docentes a participar da organização didática da disciplina conjuntamente à equipe de pedagogos e estagiários do LEAD/UERJ. Sua proposição, organização e realização seguiu os pressupostos do projeto Implementação da Licenciatura em Letras - Habilitação Português-Italiano e respectivas Literaturas, de nossa autoria e coordenação.

O projeto Implementação da Licenciatura em Letras - habilitação em Português-Italiano objetivou realizar ajustes e adequações na referida licenciatura, para que os estudantes tivessem acesso rápido à informação acadêmica, bem como ao manejo das novas 
tecnologias da comunicação e informação aplicadas ao ensino, aprendizagem e avaliação de línguas.

O processo de organização em ava da disciplina ESLIII contou com o apoio técnico do então Laboratório de Educação a Distância da UERJ - LEAD, com a participação dos estudantes nela inscritos e de estudantes-bolsistas de Iniciação à Docência - ID. Naquele momento, usamos o Laboratório de Informática do Instituto de Letras para a realização das aulas. A organização da ESLIII seguiu três eixos básicos: O da inserção do estudante no manejo do ambiente virtual - ava - Moodle; o do domínio pelo estudante da variação linguística diamésica; o da reflexão sobre as práticas de ensino e aprendizagem em ava.

Para o desenvolvimento dos eixos acima selecionamos textos, organizamos objetos virtuais, propusemos oficinas de EAD, realizamos um encontro presencial e um a distância por semana, por meio de chat, aos sábados. Tais eixos foram distribuídos por tópicos de modo que o estudante buscasse refletir sobre algumas questões fundamentais não somente a toda a pedagogia, mas também a todo fazer científico, mudando apenas o objeto, a saber: A quem ensinar? o que se vai ensinar? e como é que se vai ensinar? (GIRARD: 1997, p.158). Isso se deu em virtude de se entender que carecia ao estudante de Letras a coordenação entre a formação teórica (linguística e cultural) e a formação prática (Idem, op.cit, p.157). Um dos produtos da experiência com a ESLIII foram as I e II Jornadas de Formação Docente Tecnologia e Inovação no Ensino do Italiano, ocorridas em 2010 e 2012 respectivamente. Em 2012/1 oferecemos outra vez a disciplina ESLIII, na fase Beta, com ajustes decorrentes das observações dos estudantes-cursistas, dos estagiários, da equipe Latic e de demais colaboradores.

O processo de organização em ava da ESLIII contou em 2011/2 com o apoio da Capes/UAB, a partir da iniciativa do Latic/SR-1 UERJ que propôs o projeto institucional UERJ - PIUERJ - edital ํㅜ15/2010/Capes/DED. Com isso, obtivemos como modalidade do apoio duas bolsas-pesquisas e duas para tutoria. Esse apoio viabilizou a dedicação de duas pesquisadoras, docentes UERJ e de dois tutores, sendo um docente e outro técnico, ambos da UERJ e com formação docente em Português-Italiano. Nossa atuação se deu em duas linhas do PIUERJ, a saber: Produção de Conteúdos Educacionais e Materiais Didáticos e Fomento à Oferta de outras Disciplinas com uso de Tecnologias de Informação e Comunicação para Cursos de Graduação Presencial. Com o recebimento dos auxílios, passamos ao tratamento da disciplina em sua fase beta. Nessa fase, mantivemos a organização em tópicos, cada um com uma indagação que surge como guia às questões de fundo e de sustentação, i. é; a Filosofia Educacional. Como se trata de uma disciplina de estágio curricular em Letras, após as questões 
filosóficas educacionais, básicas às carreiras docentes, surgem aquelas referentes à área específica do conhecimento, ou seja, as linguísticas, divididas em eixos de competências, a saber: a textual, a pragmática, a oracional, a morfossintática e a fonológica.

As questões relativas ao manejo no ambiente virtual ficaram a cargo do Latic, a que solicitamos um tutorial a ser exibido e disponibilizado aos estudantes no início das atividades cursistas. Destacamos, também, que a construção da disciplina ESLIIII foi, inicialmente, em formato bilíngue - Português e Italiano, para que os estudantes destas duas línguas, nacionais e estrangeiros, pudessem ter pleno acesso a esse material no repositório do MEC. Com isso, os tópicos foram vertidos para o Italiano, bem como foram disponibilizados textos teóricos em ambas as línguas, mas neste caso, deu-se preferência aos textos originariamente produzidos em Português ou em Italiano, evitamos, portanto, traduções não autorizadas. Além disso, foi feita revisão na ESLIII com base na experiência da fase Alfa e a versão dos textos de abertura de cada tópico. Foram produzidos também vídeos e webconferências. Em vídeos contamos com relato de uma ex-aluna do curso de letras (português/italiano) sobre sua experiência enquanto estagiária de Iniciação à Docência na UERJ. Durante o período de um ano e seis meses ela participou auxiliando sua orientadora na organização e planejamento da disciplina online Estágio Supervisionado III (português/italiano) como também monitorou os alunos na execução das atividades propostas. Aqueles que se interessam pela educação a distância e também aqueles que desconhecem o ambiente de trabalho por detrás de um curso online podem a partir dessa apresentação conhecer alguns dos desafios enfrentados na organização e realização de um curso bilíngue. As webconferências trataram de questões relativas ao ensino e didática de línguas e se encontram todas disponibilizadas no Latic you tube: Experiências em tutoria semipresencial e a distância, que discutiu o modelo de formação de professores-tutores adotado pela Universidade Federal do Ceará (UFC) desde 2006, quando passou a integrar o Sistema Universidade Aberta do Brasil (UAB); A Questão da Língua Italiana que retomou a discussão sobre qual língua utilizar na península italiana; Ensino de produção escrita a distância na universidade: syllabi, estratégias e dinâmicas virtuais - relato de experiência que apresentou e discutiu a dinâmica e a estrutura de uma disciplina de produção escrita, oferecida no âmbito do curso de graduação em língua italiana da Faculdade de Letras da Universidade Federal de Minas Gerais; Recursos para a autoaprendizagem mediada; que abordou o uso da Internet para o ensino das línguas estrangeiras, inclusive a língua italiana, tendo em vista que foram criados e disponibilizados na rede vários sítios direcionados à aprendizagem do idioma de Dante e à formação docente, assim como sítios de conjugação verbal e dicionários. Contou-se ainda com uma vídeo-aula sob o título A elaboração de material didático específico para as dificuldades dos alunos 
brasileiros, ministrada por docente da USP, que deu destaque à complementação do material oferecido pelo livro didático considerando as dificuldades específicas do grupo de alunos de Italiano, lembrando que as dificuldades não são apenas linguísticas, mas acima de tudo: culturais.

\section{Considerações finais}

Ao repensarmos a disciplina ESLIII, ao acompanharmos os tutores, ao dialogarmos com a equipe Latic, os estudantes e docentes pudemos chegar a algumas considerações, tais como: Reelaborar a disciplina em duas tutorias, uma com caráter introdutório e outra de prática de estágio propriamente dita, reelabora-la em Português e em Italiano separadamente; organizar um roteiro da tutoria; manter os textos para estudo em Português e Italiano; propor, no máximo, três textos por unidade; mudar a organização em tópico para unidade; intensificar a interação nas wikis, diários e fóruns e ainda com outras instituições, através de chats, webconferências, vídeos, retomar a proposta da disciplina campo de estágio Ali on-line, testada anteriormente com estudantes do curso de Turismo da UERJ; analisar os resultados de questionários de avaliação da disciplina, organizar laboratórios de avaliação.

\section{Referências}

BALBONI, Paolo. Tecniche Didattiche per l'Educazione Lingüística - Italiano, lingue straniere, lingue classiche. Torino: UTET, 2007.

GERARD, Denis. Linguística Aplicada e Didática de Línguas. Rio de Janeiro: Editorial Estampa, 1997.

PICHIASSI, Mauro. Fondamenti di glottodidattica - temi e problemi della didattica lingüística. Perugia: Guerra, 1999.

APPRENTISSAGE des langues et citoyenneté européene. Un Cadre Européen Commun de Référence pour les Langues: apprendre, ensegner, évaluer. Conseil de L'Europe, División des Politiques Linguistiques, Strasbourg. Les Éditions Didier, Paris, 2001, p.81. Online: disponível na Internet, acesso em 21/07/2011, via http://www.coe.int/t/dg4/linguistic/source/framework_FR.pdf

BARROS, Daniela, ALVES, Lynn e OKADA, Alexandra (org). Moodle Estratégias Pedagógicas e Estudos de Caso. Salvador: EDUNEB, 2009. 
BONAIUTI G. E-learning 2.0. II Futuro nell'Apprendimento in Rete tra Formale e Informale. Trento: Erickson, 2006.

BALBONI, P. E. le Sfide di Babele - insegnare lingue nelle società complesse. Torino: UTET, 2002.

Tecniche Didattiche per l'Educazione Lingüística - Italiano, lingue straniere, lingue classiche. Torino: UTET, 2007.

BONOMI, Ilaria \& ALFONZETTI, Giovanna. Le Varietà Diafasiche e Diastratiche del Repertorio. Catania: Università di Catania/ Italian Culture on the Net. www.italiacon.it, 2003.

CALVANI A. e ROTTA M. Comunicazione e Apprendimento in Internet - Didattica Costruttivistica in Rete. Trento: Erickson, 1999.

COSERIU, Eugenio. O Homem e sua Linguagem - estudos de teoria e metodologia linguística. Rio de Janeiro: Presença, 1997. . Lições de Linguística Geral. Rio de Janeiro: Ao Livro Técnico, 1980.

DANESI, M. Neurolinguistica e glottodidattica. Padova: Liviana, 1988.

DARDANO, Maurizio \& TRIFONE, Pietro. Grammatica Italiana con Nozioni di Lingüística. Bologna: Zanichelli, 1999.

DOLCI R. e SPINELLI B. (a cura di). Educazione linguistica e interculturale in nuovi ambienti di apprendimento, supplemento monografico della Rivista Itals, anno III, nr. 9. Perugia: Guerra Edizioni, 2005.

ECO, Umberto. A Busca da Língua Perfeita na Sociedade Européia. Bauru: EDUSC, 2001.

LOPES, Edward. Fundamentos da Linguística Contemporânea. São Paulo: Cultrix, 1989.

MEZZADRI, Marco. Internet nella Didattica dell'Italiano. Perugia: Edizioni Guerra, 2001.

PAIS, Cidmar Teodoro. "Elementos para uma tipologia dos sistemas semióticos". In: Revista brasileira de Lingüística, V.6, São Paulo: Duas Cidades, 1982, p.45-60. 
PAVAN, Elisabetta. "La cultura e la civiltà italiane e il loro insegnamento in una prospettiva interculturale" In. : DOLCI, Roberto \& CELENTIN, Paola. A cura di. La Formazione di Base del docente di Italiano per Stranieri. Roma: Bonacci, 2000, p.77.

PIERINI, Letizia. Principi de Linguística Contrastiva. Roma: Università di Roma Tre/Italian Culture on the Net, www.Italicon.it, 2004.

PORCELLI, G. e DOLCI, R. Multimedialità e Insegnamenti Linguistici. Torino: UTET Libreria, 1999.

PRANZETTI, R. "I blog e i wiki in ambito didattico, in Soluzioni Open Source per la Didattica in rete nelle scuole", in Form@re - Newsletter per la formazione in rete, n. 33 febbraio 2005. Trento: Erickson, 2005. http://www.formare.erickson.it/archivio.html

SORRENTINO F. e PAGANELLI F. L'intelligenza distribuita. Ambient Intelligence: il futuro delle tecnologie invisibili. Trento: Erickson, 2006.

VARISCO B.M. Costruttivismo socio-culturale. Genesi filosofiche, sviluppi psicopedagogici, applicazioni didattiche. Roma: Carocci Editore, 2002.

VYGOTSKIJ L. S. II Processo Cognitivo. Torino: Bollati Boringhieri, 1980 